\title{
Rapid Identification of Economic Indicators of Integrated Energy Systems Based on Data Analysis
}

\author{
Wei He, ${ }^{1}$ Haicheng Lu, ${ }^{2}$ Yingfang Liu, ${ }^{3}$ Guang Chen, ${ }^{2}$ and Zishuo Huang $\mathbb{D}^{3}$ \\ ${ }^{1}$ State Grid Jiangxi Electric Power Research Institute, Nanchang 330096, China \\ ${ }^{2}$ Xu Ji Group Co. LTD, Xuchang 461000, China \\ ${ }^{3}$ College of Architecture and Urban Planning Tongji University, Shanghai 200092, China \\ Correspondence should be addressed to Zishuo Huang; zzujianhuan@163.com
}

Received 19 August 2021; Revised 12 December 2021; Accepted 19 January 2022; Published 4 February 2022

Academic Editor: Yang Li

Copyright (C 2022 Wei He et al. This is an open access article distributed under the Creative Commons Attribution License, which permits unrestricted use, distribution, and reproduction in any medium, provided the original work is properly cited.

\begin{abstract}
The construction of integrated energy systems has received widespread attention. In addition to system design and operating optimization, clarifying the internal relationship between the project's own characteristics and its economic indicators is also important for high-value project selection and implementation. Based on various energy prices and the climatic characteristics of typical cities, 60 integrated energy supply projects in 4 typical cities were used as a case study, and the cold and heat source system solutions with the shortest investment payback period for each project were calculated through a system optimization model. We calculated the correlation coefficient between the initial investment of system equipment, annual energy supply, annual energy sales revenue, annual equivalent full-load energy supply hours, initial equipment investment indicators for annual unit energy supply, and the project's static investment payback period. The key factors affecting the static investment payback period of the project were identified. The results show that, under the optimal system scheme, even for buildings of the same type in the same area, the economic indicators of different integrated energy projects are still quite different. Under the current design, operation, and operation conditions, load distribution is the decisive factor for the economic feasibility of the project. The static investment payback period of the project can be quickly calculated based on the equivalent full-load energy supply hours of the project throughout the year. Compared with the current numerical and system dynamics model for point-to-point single system optimizing modeling, the proposed statistical regression model can help reveal the main factors of integrated energy system's economically feasible.
\end{abstract}

\section{Introduction}

With the introduction of China's carbon peak carbon neutral strategy, the energy efficient of demand-side has attracted widespread attention [1]. In addition to improving the energy conversion efficiency of a single technology, the cascade complementary utilization of multiple energy sources also plays an important role in improving energy efficiency [2,3]. In this situation, comprehensive energy supply services characterized by the comprehensive and efficient utilization of multiple energy sources have attracted attention for the various energy needs of end users, such as electricity, heating, cooling, and gas $[4,5]$. The planning, design, and optimization operation research of the integrated energy supply system have focused on the overall planning and scheduling methods of energy production, conversion, storage equipment, and end energy users within the energy supply range [6-8].

One of the current research hotspots is to describe the operating characteristics of various equipment in the integrated energy supply system through physical and mathematical models and to model and optimize the structure and operation strategy of the integrated energy supply system based on energy supply and demand balance and optimization algorithms [9-11]. The planning and design of comprehensive energy supply systems mostly 
take the economy as the planning goal, supplemented by indicators such as carbon emissions, energy efficiency, and reliability, to arrive at a comprehensive and optimal plan [12]. Wei et al. established a nonlinear model considering the configuration of system equipment and optimized operation on the basis of the optimal annual cost and proposed a corresponding evaluation system and evaluation configuration plan [13]. Hung et al. proposed two levels of system planning optimization and operation scheduling optimization for the planning model of the integrated energy supply system, constructed a two-level planning mathematical model considering the economy and environmental protection, and used particle swarm optimization as the solution method [14]. Quitoras et al. took the minimum sum of the initial investment cost and operating cost as the optimization goal and carried out capacity planning of a variety of equipment in the target area containing photovoltaic and hybrid energy storage (battery and supercapacitor) energy units [15]. Keshavarzzadeh and Ahmadi constructed a comprehensive energy supply system equipment capacity configuration optimization model with the lowest energy cost of the electricity, heat, and gas subsystems, considering the energy balance of the energy system and the constraints of the energy equipment characteristics, and used the optimized area shrinkage algorithm to accelerate the solution [16]. Meesenburg et al. considered the operation optimization of the integrated energy supply system on different time scales and optimized the operation of the integrated energy supply system through hybrid time scale modeling [17]. Ge, considering the uncertainty of load demands and wind generations, proposed a novel models to optimize the capacity and location of energy storage system [18]. Mahmoudi established a multiobjective fuzzy optimization model and explored a system optimization operation plan with better economy and reliability of the integrated energy supply system [19]. Langer summarized typical optimization algorithm used for integrated energy system for buildings [20]. In order to increase the roughness of hybrid energy system, Ye et al. put forward an energy management strategy optimization method for the hybrid energy storage system based on the fuzzy control strategy [21].

Due to the dynamic fluctuation of the load and the supply capacity of some energy resources, the operation adjustment of the park-level integrated energy system has an important influence on the actual operation effect of the system [19]. The actual operation adjustment of the system needs to formulate a reasonable operation plan according to the changes in the conditions of the supplier and the demander, so as to improve the energy efficiency and economy of the system [22]. System operation control includes seasonal control, emergency guarantee, day-ahead adjustment, hourly adjustment, and time-to-time control. It is necessary to formulate optimal operation control strategies through quantitative calculations based on basic data conditions. Li et al. also proposed a novel operation method to enhance the flexibility of integrated energy system considering the uncertain of renewable generations and buildings' thermal inertia [22].
The factors that affect the economics of a comprehensive energy supply project can be divided into external decisionmaking interventions (scheme selection, purchase price, etc.) and the inherent characteristics of the project. External intervention refers to the scientific and reasonable design of the energy supply, energy storage, and transmission and distribution systems based on the available resource conditions, needs and current available energy equipment conditions of the project, and the completion of the system construction by purchasing at market prices; internal characteristics refer to the internal characteristics of the project. The temporal and spatial distribution characteristics involve the user's own demand, including the peak and valley characteristics of the demand curve and the ratio of cold and heat; the user demand is assumed to be unchangeable or is the actual energy demand after the demand response is considered. Existing research has focused on the development of the optimal configuration model of the integrated energy system with the most economical efficiency and combined it with case studies to analyze the economic indicators of different integrated energy supply projects to provide a reference for the development of integrated energy supply projects. With the current comprehensive energy technology and economic model maturation with equipment prices being transparent, external factors affecting project economics can be used as constants to establish a quantitative relationship between the project's own internal demand characteristics and project economics, which is helpful for early project screening to improve the work efficiency in stages.

This paper uses the optimal configuration model of the integrated energy supply system to determine the system plan based on the configuration of the integrated energy supply system according to the principle of optimal economics during the life cycle of the project. After adopting an integrated cooling and heating supply for representative cities and typical buildings in typical climate zones in China, the economics of the project are compared and analyzed, and the functional relationship between the economics of the project and the key influencing factors is established through multifactor analysis to quickly screen out economically feasible comprehensive energy supply projects and to provide the price of some projects with high energy sales prices. The results can provide guidance for negotiations.

\section{Typical Setting of the Integrated Energy System}

China has a vast territory, and the climate varies significantly from place to place due to different geographical latitudes, topography, and other conditions. The "Code for Thermal Design of Civil Buildings" divides the country into five thermally designed climate regions for buildings: severely cold regions, cold regions, hot summer and cold winter regions, hot summer and warm winter regions, and mild regions. Considering the use of building energy, in the 1950s, an artificial dividing line, namely, the "Qinling-Longhai Line" near $33^{\circ}$ north latitude, was used as a boundary. In the 
cities on the north side of the boundary line, the government installed a centralized heating system, while, in the cities on the south side of the line, a household heating method was adopted, and each household installs its own heating system.

The type and energy consumption of the integrated energy system involves the load intensity, the energy system form, energy supply period, and renewable energy resource conditions. Since the northern heating area adopted central heating system in the winter, the difference between the cities is mainly the difference in energy consumption caused by the difference in coldness, which has no essential influence on the form of the integrated energy system. Therefore, a typical city is selected, and the city is different. The case of load intensity reflects the difference in coldness. The nonheating areas in the south are mainly the Yangtze River Basin, the Pearl River Basin, and the Yunnan-Guizhou region in southwestern China. There are large differences in the energy demand between winter and summer, which have a significant impact on the form of the energy system. For example, the Yangtze River Basin is hot in the summer and cold in the winter, requiring both heating in winter and cooling in summer. Guangzhou and Shenzhen in the Pearl River Delta area mainly require cooling in the summer, and there is almost no heating demand in winter. The climate in Yunnan and Guizhou is mild, and the energy demand in both the winter and summer is small. In addition, the forms of building energy systems and the energy use characteristics of different building types are quite different. Three representative cities were chosen to reflect the differences in climate. Considering the large difference in energy consumption by industrial enterprises, this research focused on the analysis of large-scale residential, office, and commercial buildings.

Comprehensive climate zoning and the current status of the city's existing cooling and heating municipal facility system construction were considered. This study selected 4 typical cities, as shown in Table 1, compared the indicators of the integrated energy supply system for 15 buildings, including residential, office, and commercial buildings, and conducted a comparative analysis.

\section{Optimization of the Integrated Energy System}

The integrated energy supply system converts resources such as electricity, gas, and solar energy into chilled water, hot water and electricity as required by the users. The integrated energy conversion system can be regarded as a generation system that provides users with various "energy products." According to the various energy needs of users, the production system combines the price and input and output performance of various energy conversion equipment, and an economically optimal configuration plan can be obtained by establishing a supply-demand balance model. In most integrated energy supply projects, electricity mainly relies on the large grid as a "reservoir": when it is insufficient, it is purchased from the large grid and sent back to the large grid when there is surplus power. The characteristics of the highdensity cities also determine the general terminal power interaction. The transaction demand is small. In addition, the gas supply service is mainly profitable from the pure market purchase and sale of gas prices and does not involve complex system conversion links, and its economics are not discussed here. This section mainly discusses the centralized supply service of cold and heat.

3.1. Optimization Model of Integrated Energy Systm. For the optimization of the integrated energy system, the main goal is to determine the equipment configuration scheme of the system. Therefore, it is necessary to simulate and model the equipment based on the input and output characteristic data of the equipment under different conditions and describe its input and output characteristics more accurately. And we need to analyze the dynamic characteristics of the system, by calculating the input and output characteristics of the system in different states, based on the statistical analysis of the system operation results in different scenarios, and determine the design parameters of the system and each device.

Common energy conversion technologies (ECT) in integrated energy system of the park mainly include gas generating units, lithium bromide absorption units, electric refrigeration units, heat pumps, gas boilers, and photovoltaics. Under normal circumstances, the supply-side ECT equipment investment generally occurs in the construction stage of the park's integrated energy system project, and the operating costs usually occur in the project operation stage. In this article, the equivalent annual value method (UAVM) is used to convert the initial investment of the ECT on the supply side of the park's integrated energy system into an equivalent initial investment in the entire life cycle of the project. On this basis, the equivalent annual operating hours $(\mathrm{AEOH})$ are used to convert the initial investment of the equivalent annual value into the initial investment at each operating time. Then, the hourly operating costs and maintenance costs are superimposed on the hourly initial investment to obtain the technical cost level of the supply. The mathematical expression is shown in the following equations:

$$
\begin{aligned}
S_{\tau, \text { total }} & =\sum_{j} S_{\tau, j}, \\
S_{\tau, j} & =C_{i n, \tau, j}+C_{o, \tau, j}+C_{m, \tau, j},
\end{aligned}
$$

Here, $S_{\tau \text {,total }}$ is the total cost of energy conversion in time $\tau$, $\$$; $S_{\tau, j}$ is the cost of ECT, whose number is $j$ in time $\tau, \$ ; C_{i n, \tau, j}$ is the initial investment cost sharing of ECT whose number is $j$ in time $\tau, \$ ; C_{o, \tau, j}$ is the operation cost of ECT whose number is $j$ in time $\tau, \$ . C_{m, \tau, j}$ is the other cost of ECT whose number is $j$ in time $\tau, \$$.

Substituting system parameters such as equipment price and operating cost, equation (2) can be expressed as equation (3).

$$
S_{\tau, \text { total }}=\sum_{j}\left[\left(a_{j}+b_{j}+\varphi_{j}\right) \frac{\max ^{2}\left(Q_{\tau, j}\right)}{\sum_{\tau=1}^{8760} Q_{\tau, j}}+\left(\beta_{j}+\varepsilon_{j}\right) Q_{\tau, j}\right],
$$

Here, $\tau=1,2, \ldots, 8760$ means the hourly time series in a year; $a_{j}, b_{j}, \varphi_{j}, \beta_{j}, \varepsilon_{j}$ are related to the cost of initial 
TABLE 1: Typical project used for the case study.

\begin{tabular}{lccll}
\hline NO. & Area & Climate zone & Building type & Case amount \\
\hline 1 & Xi'an & Cold winter mild summer & Residential, office, hotel, commercial complex & 15 \\
2 & Shanghai & Hot summer cold winter & Residential, office, hotel, commercial complex & 15 \\
3 & Guangzhou & Hot summer warm winter & Residential, office, hotel, commercial complex & 15 \\
4 & Guiyang & Mild climate & Residential, office, hotel, commercial complex & 15 \\
\hline
\end{tabular}

investment cost sharing, energy expenditure, and other costs of ECT whose number is $j$.

The energy demand and supply of the integrated energy system of the park change from time to time, and the adjustment cost also changes from time to time. Operating strategies are switched in a day or hour by hour, when load variation operators can adjust the system by starting and stopping each device or adjusting its load rate. The integrated energy system generally includes multiple energy equipment. Due to the impact of time-of-use electricity prices, the energy supply and operation costs of each energy equipment at different times are different. When calculating hourly throughout the year, the startup sequence of various energy conversion equipment at each time is as follows: when the equipment with the lowest energy supply cost will be put into operation first, and the equipment with the second lowest cost is put into operation, when the capacity of equipment with lowest cost is insufficient, until all the equipment is put into operation.

The integrated energy system of the park pursues the maximization of the overall benefits of the system in the process of matching supply and demand, that is, the minimum sum of the technical cost levels of energy supply and energy demand. Based on the energy supply and energy demand regulation level model, a supply and demand matching model with simultaneous changes in supply and demand is constructed, as shown in equations (4) to equation (6).

$$
\begin{gathered}
g(\tau)=\min S_{\tau, \text { total }} \\
g(\tau)=\min \left(\sum_{j} \int\left(\frac{\partial S_{\tau, j}}{\partial Q_{\tau, j}}\right) \mathrm{d} Q+\int\left(\frac{\partial M_{\tau, j}}{\partial D_{\tau, j}}\right) \mathrm{d} D\right), \\
\text { const } \cdot\left\{\begin{array}{l}
\Delta Q_{\tau, \text { total }}+\Delta D_{\tau, \text { total }} \leq\left|D_{\tau}^{0}+Q_{\tau}^{0}\right|, \\
0 \leq Q_{\tau, j} \leq Q_{m, j}, \\
D_{\tau, j} \leq D_{m, j},
\end{array}\right.
\end{gathered}
$$

Here, $g(\tau)$ represents the lowest technical cost for the exact matching of supply and demand at time $\tau$; $\Delta Q_{\tau, \text { total }}$ and $\Delta D_{\tau \text {,total }}$ are the total changes of supply and demand in the matching process separately; $Q_{\tau}^{0}$ and $D_{\tau}^{0}$ are the initial supply and demand value at time $\tau$, respectively; $Q_{m, j}$ and $D_{m, j}$ represent the upper limit of the output of technology $j$ limited by natural resources or environmental conditions; $\partial S_{\tau, j} / \partial Q_{\tau, j}$ is defined as the marginal technology of technology $j$ cost, and its physical meaning is as follows: for every unit of output of technology $j$, there is an increase in the level of technology cost. In a park-scale integrated energy system, the marginal costs of all energy conversion technologies at $\tau$ show an increasing law, which means that, for each additional unit of output of each technology, the technology cost level shows a rapid increase trend. Therefore, in the process of matching the supply and demand of the integrated energy system in the park to maximize the overall benefits, in order to achieve this goal, it can be proved that the principle of equal marginal technology costs must be followed when choosing ECT.

$$
\frac{\partial S_{\tau, 1}}{\partial Q_{\tau, 1}}=\frac{\partial S_{\tau, 2}}{\partial Q_{\tau, 2}}=\cdots \frac{\partial M_{\tau, 1}}{\partial D_{\tau, 1}} .
$$

Based on the technical and economic characteristics of the park's integrated energy system energy conversion technology and demand management and control, an energy supply system configuration optimization model has been established, which can quantify the dynamic costs of various technical equipment and demand response on the supply side and the demand side of the park and obtain different demand scenarios under the optimal system operation results. Using the above model, the technical and economic indicators of different comprehensive energy supply projects can be calculated based on users input heat and cooling demand matrix, whose matrix have 8760 rows.

In the following calculations, the above models will be used to calculate the technical and economic indicators of different projects. Combining China's current energy equipment prices, operation and maintenance costs, and energy prices, the main parameter settings in the model are shown in Table 2.

3.2. Energy Load of Typical Buildings. Clarifying the load of users within the service scope of the integrated energy supply project is a prerequisite for the design of the integrated energy supply scheme of the project. In the context of peak- 
TABLE 2: The value of the ECT economic parameters.

\begin{tabular}{|c|c|c|c|c|c|}
\hline ECT Technologies & $\varphi_{j} /\left(\$ \cdot \mathrm{kW}^{-1}\right)$ & $b_{j}\left(\$ \cdot \mathrm{kW}^{-1}\right)$ & $\beta_{j} /\left(\$ \cdot(\mathrm{kW} \cdot \mathrm{h})^{-1}\right)$ & $\varepsilon_{j} /\left(\$ \cdot(k W \cdot h)^{-1}\right)$ & $a_{j} /\left(\$ \cdot \mathrm{kW}^{-1}\right)$ \\
\hline Gas turbin & 17.08 & 2.08 & 0.02 & 0.12 & 0.00 \\
\hline Lithium bromide absorption units & 7.58 & 1.91 & 0.00 & 0.00 & 0.00 \\
\hline Chiller & 5.67 & 1.91 & 0.00 & 0.02 & 4.31 \\
\hline Heat pump & 6.97 & 1.91 & 0.00 & 0.04 & 4.31 \\
\hline Gas boiler & 2.44 & 1.51 & 0.00 & 0.08 & 0.00 \\
\hline
\end{tabular}

to-valley electricity prices in most areas and the time-to-time change of renewable energy resources, the same energy demand at different times means different energy supply costs. Therefore, in the design of the integrated energy system, it is necessary to optimize the system scheme based on the hourly load throughout the year.

It is currently the usual method to obtain an hourly cooling and heating load of $8760 \mathrm{~h}$ throughout the year through the building load simulation forecast tool. There are six factors affecting building energy consumption, namely, climate, building envelope, building equipment, operation and maintenance, human behavior, and indoor environmental quality. The description method of the "object" physical system of the building envelope, building equipment, and even the climate data is relatively mature, and the calculation error of the heat and cold transfer can be controlled within $10 \%$ [23]. However, most of the energy consumption in the building load is caused by the actual use of people. Due to the randomness of users' daily activities, it is difficult to accurately predict the hourly cooling, heating, and electrical load of an in-use building in practice [24].

At present, when using load simulation calculation software for load forecasting, although it is not possible to accurately predict the hourly load of buildings, by setting typical behavior patterns, the load range of a given building type can be obtained, and the hourly load of typical building types can be obtained along with the characteristics of the load. Existing building energy consumption statistics also show that, through the calculation of building energy simulation software EnergyPlus, Dest, and e-quest and other load forecasting software, the annual energy consumption forecast error can be controlled at approximately 15\%, providing guidance for engineering design $[25,26]$.

Based on this, in this study, the typical meteorological year data of the area were used to construct a typical building model in combination with the requirements of the local building energy conservation code regarding building thermal engineering to obtain the hourly cooling and heating load indicators per unit area. The cross-counting calculations of 128 buildings show that the thermal performance of different buildings has a small impact on the load, especially for buildings constructed in accordance with the engineering standards at that time in the past 20 years. The difference in energy consumption is generally approximately $10 \%$, which is close to the results of existing research.

Through the above different settings, in each city, we selected 5 typical buildings for residential, office, commercial, hotel, and complex, and each building sets its use mode of low, medium, high, and 3 medium intensity to obtain 15 types of hourly load curves throughout the year as the load source of the system configuration plan. Among them, the selection of typical buildings considers the differences in local energy intensity, changes in the thermal performance parameters of the building, the user's use period, and the indoor temperature and humidity level. Through the cross-simulation calculation of 128 buildings, according to the total annual cooling and heating, the three-point method obtains the buildings closest to one-third of the high, middle, and low typical buildings.

3.3. System Design of the Integrated Energy System. Integrated energy system design is the use of systematic scientific ideas and methods to design a process that can maximize the goal (or purpose). The integrated energy system model introduced in Section 3.1 is used to support the design. Through comprehensive consideration of various energy requirements, various energy resources, and different energy conversion technologies and equipment, combined with the economic, energy efficiency, and safety goals of the system design, the energy supply zone, the optimal design capacity, and equipment of the system are determined through a quantitative analysis model configuration.

One is to ignore the impact of the scale of the energy supply system on the cost. In projects with an energy supply area of tens of thousands to hundreds of thousands of square meters, the scale of the project is relatively large. In the calculation, it is assumed that there are no obvious differences when the purchase cost of the same equipment for projects of different scales is converted to a unit building area.

The second is that there are no restrictions on the application of common typical energy supply equipment, and the optimal multiple equipment combination schemes can be obtained according to the system optimization requirements. In addition, each case uses a widely used small air source direct expansion heat pump system (such as multiline, split heat pump air conditioning systems, collectively referred to as VRV) as the benchmark plan and calculates the technical and economic indicators of the case when the benchmark plan is adopted.

The third is that the energy supply system operates in accordance with the economically optimal principle during daily operation; that is, the equipment with the lowest production cost at this time is turned on first, and when its installed capacity is insufficient, the equipment with the second lowest energy supply cost at that time will be turned on as the energy supply, and so on. Based on this assumption, the system scheme is designed, and the annual operating results are calculated. 
The fourth is to consider the individualized differences of renewable energy resources. The most common highdensity urban areas are the research objects in this study. Due to the high development intensity and high building density, the proportion of renewable energy utilization in this type of urban area is extremely low (generally 1\%). The economics of the most commonly used photovoltaic solar thermal project can be calculated relatively independently, and the use of renewable energy is not considered for the time being.

According to the above assumptions, based on the current electricity price and gas price of each city, the cooling and heating price is $0.08 \$ / \mathrm{kWh}$, and the optimal design method of the multienergy complementary integrated energy system is used to obtain the optimal integrated energy supply plan in 60 cases and benchmark schemes.

\section{Economic Comparison of Different Integrated Energy Systems}

It can be seen from the complexity of the level integrated energy system itself and the requirements of the planning, design, and optimization operation stages that it is difficult for personal experience to meet the requirements of the project. The optimization calculation through the simulation model and the corresponding decision-making based on the calculation data produces the integrated energy system. The inevitable choice of construction according to the basic principles of optimization leads to the research results of the current-level integrated energy system optimization model being sorted and classified.

4.1. Benchmark System. Taking the VRV air-conditioning system as the benchmark scheme of the energy supply system, the technical and economic indicators shown in the following table (taking Shanghai as an example) are obtained through the close calculation of the system running hourly throughout the year. The net income in Table 3 refers to the income from hot and cold sales minus the cost of purchasing electricity and gas and equipment maintenance. The static investment payback period calculation only considers the purchase and installation cost of the energy conversion system equipment and does not consider the energy station building civil construction or the computer and land cost. According to the actual operating statistics of direct expansion air-conditioning equipment with existing air sources heat pumps [27, 28], the average annual cooling energy efficiency of VRV equipment is set to 3.2, and the annual average heating energy efficiency is set to 2.6. All energy system schemes in this article follow this setting during calculations.

The same set of calculations obtains the results for when the VRV system is adopted for typical buildings in the three cities of Guangzhou, Beijing, and Guizhou.

4.2. Basic Set of the Optimized System. Given the hourly cooling and heating requirements, the technical and economic parameters of the various system equipment, and the energy prices, determining a comprehensive energy supply system plan is mainly mediated through a method of system optimization models.

The energy conversion system and its price and annual average energy efficiency value considered in the calculation are shown in Table 4. Listed in the table are the overall converted price and energy efficiency of the energy conversion system with cold and heat energy output functions, including cold and heat conversion equipment, a cooling tower (if any), water treatment and other ancillary equipment and pipe fittings inside the energy station, excluding the price of the external pipe network and the facilities of the energy station.

Through the optimization calculation, the system scheme with the shortest static investment payback period of each typical building is obtained. The optimal schemes of various types of typical buildings in different cities are shown in Table 5.

As mentioned earlier, the static investment payback period presented in the table only calculates the cost of cold and heat source equipment, without considering the cost of construction and installation and the cost of the computing. It can be seen from Table 5 that when there is no use of lowgrade or low-cost renewable energy resources, the static investment payback period of most comprehensive energy supply projects is relatively long.

\section{Results and Discussion}

Through simulation calculations of various comprehensive energy supply systems hourly throughout the year, combined with the economic results of 60 different energy supply systems, we explore the common law of the economic changes of comprehensive energy supply projects.

5.1. Economic Indicators of the Benchmark System. In hot summer and cold winter areas, the air source direct expansion heat pump system represented by VRV is the most commonly used heating and cooling dual cooling and heat source equipment, accounting for more than $40 \%$ of the centralized energy supply system alone [29]. Considering its application in residents, small offices, and small commercial buildings, this type of system is currently the most common cold and heat source equipment.

Figure 1 shows the economic results of VRV system application in 60 typical buildings in 4 typical cities.

Because the load distribution of different buildings is not the same, the economics of using the same priced VRV system are quite different. The relationships among different influencing factors and the economics of the energy supply projects are shown in Table 6 below. Among them, each variable is converted into the index value per square meter of building area or per $\mathrm{kWh}$, and the investment payback period is in years.

It can be seen from Table 6 that although different projects have different load characteristics, and the energy prices are not nearly the same, the project economic indicators (the static investment payback period) and the annual equivalent full-load energy supply hours are relatively 
TABLE 3: Technical-economic indicators of the reference system (Shanghai).

\begin{tabular}{|c|c|c|c|c|c|c|c|}
\hline Case & $\begin{array}{c}\text { System capacity } \\
\text { indicators } \\
\left(\mathrm{W} / \mathrm{m}^{2}\right)\end{array}$ & $\begin{array}{l}\text { Yearly cold } \\
\text { demand } \\
\left(\mathrm{kWh} / \mathrm{m}^{2}\right)\end{array}$ & $\begin{array}{c}\text { Yearly thermal } \\
\text { demand } \\
\left(\mathrm{kWh} / \mathrm{m}^{2}\right)\end{array}$ & $\begin{array}{l}\text { Yearly energy } \\
\text { sale proceeds } \\
\text { (\$/year) }\end{array}$ & $\begin{array}{l}\text { System initial } \\
\text { investment } \\
\left(\$ / \mathrm{m}^{2}\right)\end{array}$ & $\begin{array}{c}\text { Static } \\
\text { payback time } \\
\text { (year) }\end{array}$ & $\begin{array}{c}\text { Energy } \\
\text { consumption } \\
\text { indicator } \\
\left(\mathrm{kgce} / \mathrm{m}^{2}\right) \\
\end{array}$ \\
\hline Office 1 & 152.4 & 96.59 & 51.96 & 43.51 & 182.8 & 10.53 & 4.20 \\
\hline Office 2 & 120.6 & 66.13 & 27.48 & 28.27 & 145.32 & 8.57 & 5.14 \\
\hline Office 3 & 89.53 & 83.50 & 40.23 & 36.74 & 107.42 & 9.65 & 2.92 \\
\hline Hotel 1 & 106.77 & 93.09 & 6.20 & 39.92 & 128.13 & 3.21 & 9.79 \\
\hline Hotel 2 & 143.24 & 117.79 & 32.44 & 59.46 & 171.89 & 2.89 & 15.43 \\
\hline Hotel 3 & 73.24 & 63.86 & 15.57 & 31.56 & 87.89 & 2.79 & 8.12 \\
\hline Hotel 1 & 277.06 & 151.42 & 19.38 & 54.96 & 332.47 & 6.05 & 17.07 \\
\hline Hotel 2 & 207.71 & 82.56 & 18.43 & 31.15 & 249.25 & 8.00 & 10.28 \\
\hline Hotel 3 & 190.06 & 103.87 & 15.13 & 38.18 & 228.07 & 5.97 & 11.94 \\
\hline Residential 1 & 247.88 & 71.31 & 40.93 & 42.79 & 297.45 & 6.95 & 11.98 \\
\hline Residential 2 & 164.20 & 55.66 & 21.14 & 29.76 & 197.04 & 6.62 & 8.01 \\
\hline Residential 3 & 85.48 & 38.46 & 11.19 & 19.89 & 102.58 & 5.16 & 5.11 \\
\hline Complex 1 & 192.42 & 111.99 & 28.46 & 47.00 & 230.91 & 4.91 & 14.38 \\
\hline Complex 2 & 138.77 & 86.56 & 26.34 & 39.21 & 166.53 & 4.25 & 11.65 \\
\hline Complex 3 & 152.31 & 83.72 & 25.34 & 36.30 & 182.77 & 5.04 & 11.25 \\
\hline
\end{tabular}

TABle 4: Technical-economic indicators of the reference system (Shanghai).

\begin{tabular}{lcccc}
\hline Equipment & Output & Efficiency & Equipment price $(\$ / \mathrm{kW})$ & Equipment maintenance costs $(\$ / \mathrm{kw} / \mathrm{year})$ \\
\hline Gas boiler & Heating & 0.86 & 63.08 & 3.08 \\
Chiller & Cooling & 3.4 & 230.77 & 20.00 \\
Air source het pump & Cooling & 3.2 & 338.46 & 0 \\
& Heating & 2.5 & 738.46 & 20.00 \\
Ground source heat pump & Cooling & 3.8 & & 76.92 \\
& Heating & 3.2 & 1000 & 34.62 \\
Gas cogeneration & Cooling & 0.38 & & 34.62 \\
\multirow{2}{*}{ Energy tower } & Heating & 0.38 & 246.15 & \\
\hline
\end{tabular}

TABLE 5: Economic optimality solution of typical buildings.

\begin{tabular}{|c|c|c|c|c|}
\hline Static pay-back time (Year) & Xi'an & Shanghai & Guiyang & Guangzhou \\
\hline Office 1 & 4.38 & 4.57 & 4.59 & 2.92 \\
\hline Office 2 & 4.37 & 4.42 & 5.16 & 2.93 \\
\hline Office 3 & 4.38 & 4.50 & 4.89 & 2.93 \\
\hline Hotel 1 & 2.45 & 1.67 & 5.83 & 1.09 \\
\hline Hotel 2 & 2.43 & 1.85 & 5.82 & 1.13 \\
\hline Hotel 3 & 2.45 & 1.83 & 5.33 & 1.11 \\
\hline Hotel 1 & 4.12 & 3.93 & 4.98 & 2.61 \\
\hline Hotel 2 & 4.22 & 4.35 & 4.98 & 2.61 \\
\hline Hotel 3 & 4.10 & 4.01 & 5.16 & 2.61 \\
\hline Residential 1 & 4.11 & 3.79 & 11.23 & 4.45 \\
\hline Residential 2 & 4.25 & 3.63 & 10.67 & 3.92 \\
\hline Residential 3 & 3.14 & 3.82 & 11.17 & 4.72 \\
\hline Complex 1 & 2.74 & 3.13 & 3.45 & 2.04 \\
\hline Complex 2 & 2.62 & 2.68 & 3.46 & 2.07 \\
\hline Complex 3 & 2.63 & 3.13 & 3.82 & 1.97 \\
\hline
\end{tabular}

related. Since the same VRV system is adopted, the initial investment per unit energy supply and the annual equivalent full-load energy supply hours, the annual cooling heat per unit area, and the energy sales revenue are all highly correlated variables. We chose one of the two as an independent variable. The regression analysis of the static investment 


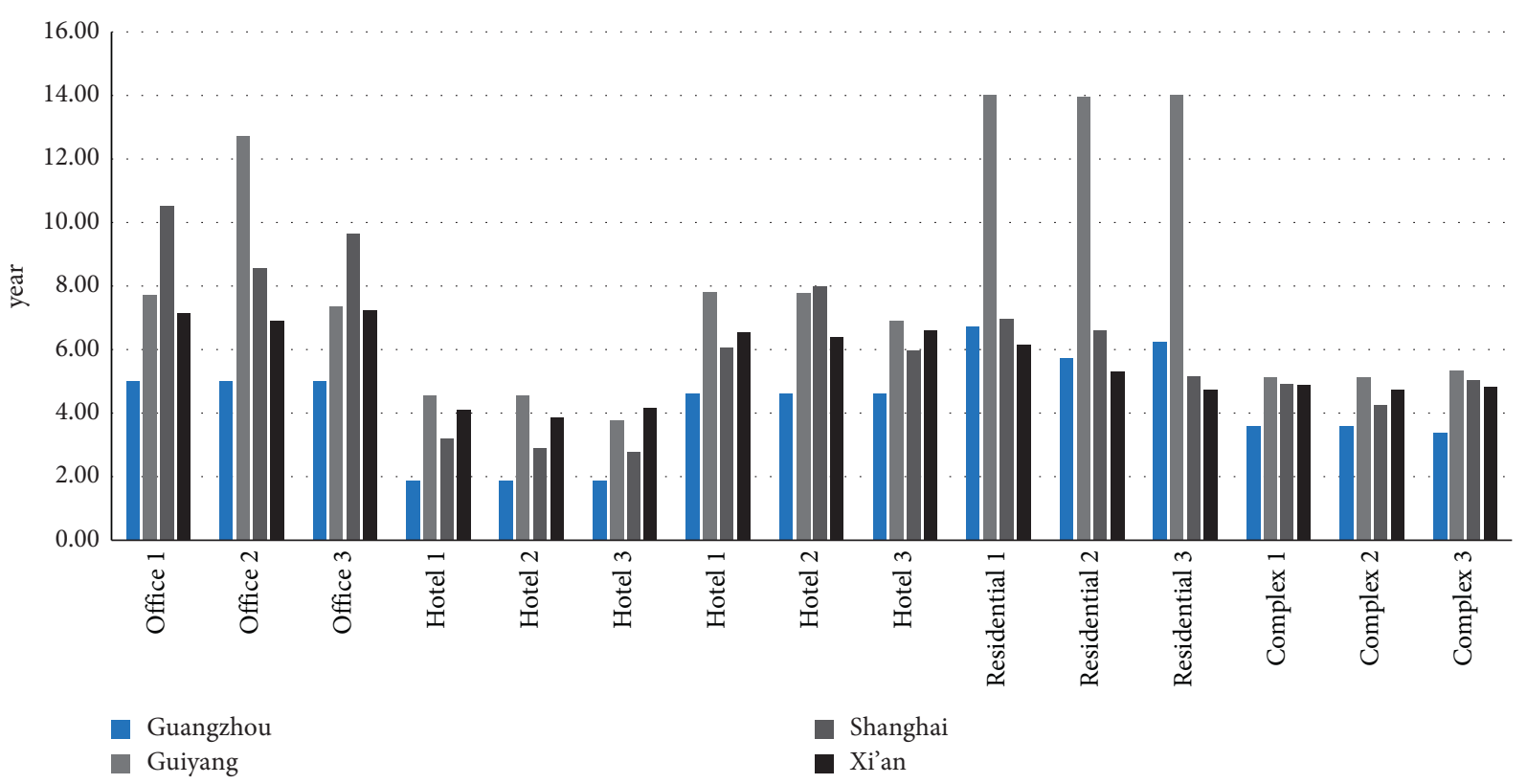

FIgURE 1: Results of VRV used in different buildings.

TABLE 6: Coefficient among different indicators with VRV.

\begin{tabular}{|c|c|c|c|c|c|c|c|}
\hline Coefficient of association & $\begin{array}{c}\text { Design load } \\
\text { indicator } \\
\left(\mathrm{W} / \mathrm{m}^{2}\right)\end{array}$ & $\begin{array}{c}\text { Initial } \\
\text { investment } \\
\left(\$ / \mathrm{m}^{2}\right)\end{array}$ & $\begin{array}{c}\text { Yearly } \\
\text { energy sale } \\
\left(\mathrm{kwh} / \mathrm{m}^{2} /\right. \\
\text { year })\end{array}$ & $\begin{array}{c}\text { Equivalent full } \\
\text { load power } \\
\text { hours per year } \\
\text { (h) }\end{array}$ & $\begin{array}{c}\text { Yearly energy } \\
\text { sale proceeds } \\
\left(\$ / \text { year } / \mathrm{m}^{2}\right) \\
\left(\$ / \mathrm{m}^{2}\right)\end{array}$ & $\begin{array}{c}\text { Static } \\
\text { payback } \\
\text { time (year) }\end{array}$ & $\begin{array}{c}\text { Initial investment } \\
\text { per unit energ- } \\
\text { production } \\
(\$ / \mathrm{kWh})\end{array}$ \\
\hline $\begin{array}{l}\text { Design load indicator } \\
\left(\mathrm{W} / \mathrm{m}^{2}\right)\end{array}$ & 1.00 & & - & - & - & - & - \\
\hline Initial investment $\left(\$ / \mathrm{m}^{2}\right)$ & 1.00 & 1.00 & - & & - & - & - \\
\hline $\begin{array}{l}\text { Yearly energy sale (kwh/ } \\
\mathrm{m}^{2} / \text { year) }\end{array}$ & 0.46 & 0.46 & 1.00 & - & - & - & - \\
\hline $\begin{array}{l}\text { Equivalent full load } \\
\text { power hours per yea (h) }\end{array}$ & -0.53 & -0.53 & 0.48 & 1.00 & - & - & - \\
\hline $\begin{array}{l}\text { Yearly energy sale } \\
\text { proceeds }\left(\$ / \text { year } / \mathrm{m}^{2}\right) \\
\left(\$ / \mathrm{m}^{2}\right)\end{array}$ & 0.30 & 0.30 & 0.99 & 0.61 & 1.00 & - & - \\
\hline $\begin{array}{l}\text { Static payback time } \\
\text { (year) }\end{array}$ & 0.44 & 0.44 & -0.55 & -0.95 & -0.67 & 1.00 & - \\
\hline $\begin{array}{l}\text { Initial investment per } \\
\text { unit energ-production } \\
(\$ / \mathrm{kWh})\end{array}$ & 0.45 & 0.45 & -0.55 & -0.96 & -0.67 & 1.00 & 1.00 \\
\hline
\end{tabular}

payback period and the annual equivalent full-load energy supply hours when the VRV system was adopted for 60 projects is shown in Figure 2.

Figure 3 shows that the economy of the VRV system depends on the annual equivalent full load hours of the project and can be predicted by the annual equivalent full load hours. The regression error predicted by the regression calculation formula is shown in Figure 3. Using the regression relationship between the annual equivalent full-load energy supply hours and the static investment recovery period for prediction, the maximum error of 60 projects is $11.86 \%$, and the average error is $5.33 \%$. From the error distribution shown in Figure 4, it can be seen that it is feasible to predict the static payback period of different users when the VRV system is adopted by the user's annual equivalent full-load energy supply hours.

5.2. Economic Indicators of the Optimized Integrated Energy System. According to the aforementioned common energy conversion equipment, based on the system design optimization model, the system scheme with the shortest static investment payback period for each project is obtained. The static payback period for each of the 60 projects is shown in Figure 4 .

Compared with all projects adopting the VRV system, through the optimized design, when 60 projects adopt the 


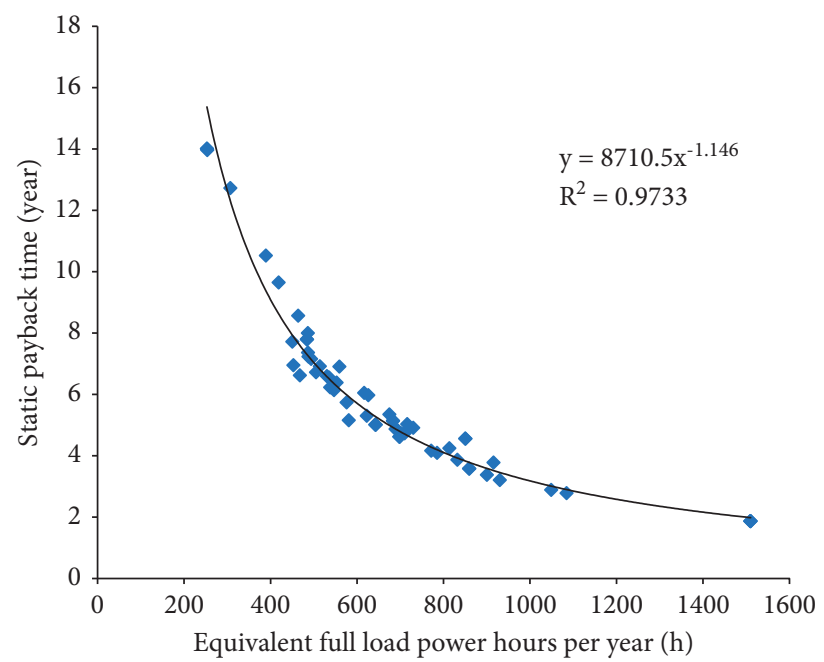

FIgURE 2: The relationship between payback-years and full load hours with VRV.

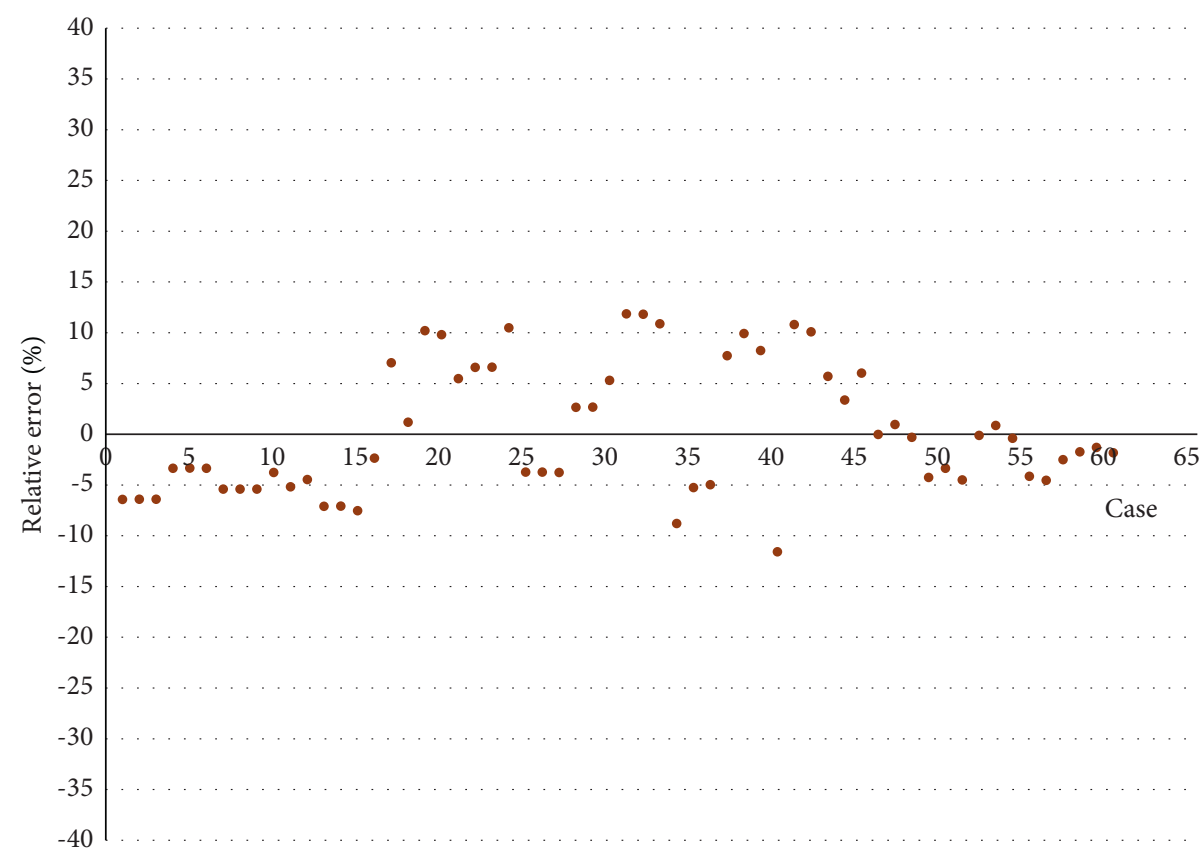

FIGURE 3: Forecast error based on the regression relationship with VRV.

solution with the shortest static investment payback period, the average payback period is shortened by 2.08 years, which reflects the economic value of the optimized design.

Similarly, when each project adopts the energy supply and consumption plan with the shortest static investment recovery period, the correlation between different influencing factors and the static investment recovery period is shown in Table 7.

It can be seen from Table 7 that, due to the differences in the system schemes of different projects, the correlation between the project's static investment payback period and the annual equivalent full-load energy supply hours has decreased, but it is still relatively high. In addition, due to different system schemes, the impact of energy price differences has expanded, and the energy sales revenue per unit building area has a greater correlation with the static investment recovery period. We conducted regression analysis on the static investment payback period and the annual equivalent full-load energy supply hours of the 60-project economic optimal schemes, and the results are shown in Figure 5. It is worth noting that the static investment payback period in the figure is only the cost of the energy system equipment and does not include the energy station building cost, construction and installation, or other costs. The actual project payback period will be 1.8-3.2 times the calculation result. 


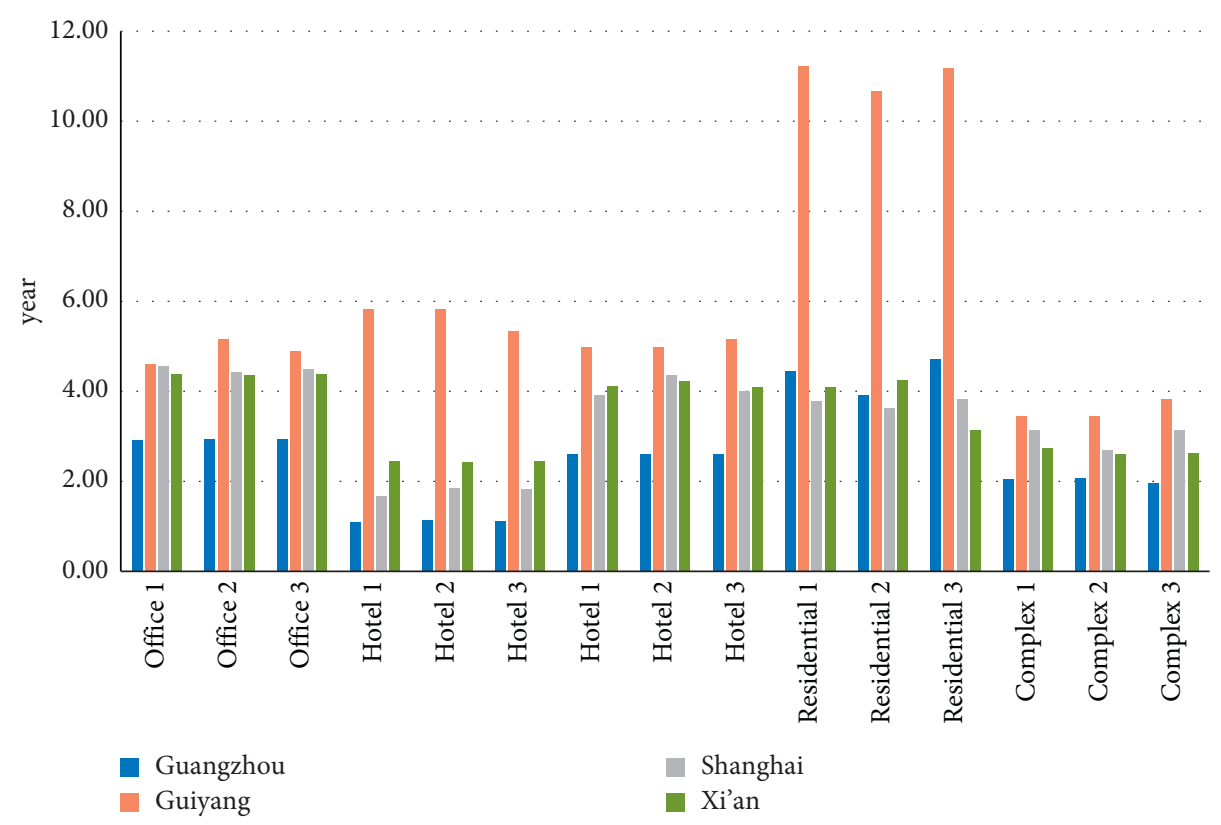

FIgURE 4: Comparison of the shortest payback year in different buildings.

TABLE 7: Coefficient among different indicators with economy-first solutions.

\begin{tabular}{|c|c|c|c|c|c|c|c|}
\hline $\begin{array}{l}\text { Coefficient of } \\
\text { association }\end{array}$ & $\begin{array}{c}\text { Design load } \\
\text { indicator } \\
\left(\mathrm{W} / \mathrm{m}^{2}\right)\end{array}$ & $\begin{array}{l}\text { Initial } \\
\text { investment } \\
\left(\$ / \mathrm{m}^{2}\right)\end{array}$ & $\begin{array}{c}\text { Yearly } \\
\text { energy sale } \\
\left(\mathrm{kwh} / \mathrm{m}^{2} /\right. \\
\text { year })\end{array}$ & $\begin{array}{l}\text { Equivalent full } \\
\text { load power hours } \\
\text { per year }(\mathrm{h})\end{array}$ & $\begin{array}{c}\text { Yearly energy } \\
\text { sale proceeds } \\
\left(\$ / \text { year } / \mathrm{m}^{2}\right) \\
\left(\$ / \mathrm{m}^{2}\right)\end{array}$ & $\begin{array}{c}\text { Static } \\
\text { payback } \\
\text { time (year) }\end{array}$ & $\begin{array}{c}\text { Initial investment } \\
\text { per unit energ- } \\
\text { production } \\
(\$ / \mathrm{kWh})\end{array}$ \\
\hline $\begin{array}{l}\text { Design load } \\
\text { indicator }\left(\mathrm{W} / \mathrm{m}^{2}\right)\end{array}$ & 1.00 & - & - & - & - & - & - \\
\hline $\begin{array}{l}\text { Initial investment } \\
\left(\$ / \mathrm{m}^{2}\right)\end{array}$ & 0.92 & 1.00 & - & - & - & - & - \\
\hline $\begin{array}{l}\text { Yearly energy sale } \\
\left(\mathrm{kwh} / \mathrm{m}^{2} / \text { year }\right)\end{array}$ & 0.46 & 0.39 & 1.00 & - & - & - & - \\
\hline $\begin{array}{l}\text { Equivalent full load } \\
\text { power hours per } \\
\text { yea }(h)\end{array}$ & -0.53 & -0.51 & 0.48 & 1.00 & - & - & - \\
\hline $\begin{array}{l}\text { Yearly energy sale } \\
\text { proceeds }(\$ / \text { year/ } \\
\left.\mathrm{m}^{2}\right)\left(\$ / \mathrm{m}^{2}\right)\end{array}$ & 0.19 & 0.17 & 0.96 & 0.69 & 1.00 & - & - \\
\hline $\begin{array}{l}\text { Static payback time } \\
\text { (year) }\end{array}$ & 0.36 & 0.49 & -0.57 & -0.86 & -0.70 & 1.00 & - \\
\hline $\begin{array}{l}\text { Initial investment } \\
\text { per unit energ- } \\
\text { production } \\
(\$ / \mathrm{kWh})\end{array}$ & 0.34 & 0.52 & -0.54 & -0.83 & -0.66 & 0.98 & 1.00 \\
\hline
\end{tabular}

Figure 5 shows that the economics of the optimal economic scheme still depend on the annual equivalent full load hours of the project and can be predicted by the annual equivalent full load hours. The regression error predicted by the regression calculation formula is shown in Figure 6. Using the regression relationship between the annual equivalent full-load energy supply hours and the static investment recovery period for prediction, the maximum error of 60 projects is $18.96 \%$, and the average error is
$10.22 \%$. It can be seen from the error distribution in Figure 6 that, for the economically optimal system scheme, it is feasible to predict the static investment payback period when different users adopt the VRV system through the equivalent full-load energy supply hours of the project. However, due to the differences in the system schemes adopted by different projects, the accuracy of its prediction is better as compared with the prediction error when both VRV systems are used. 


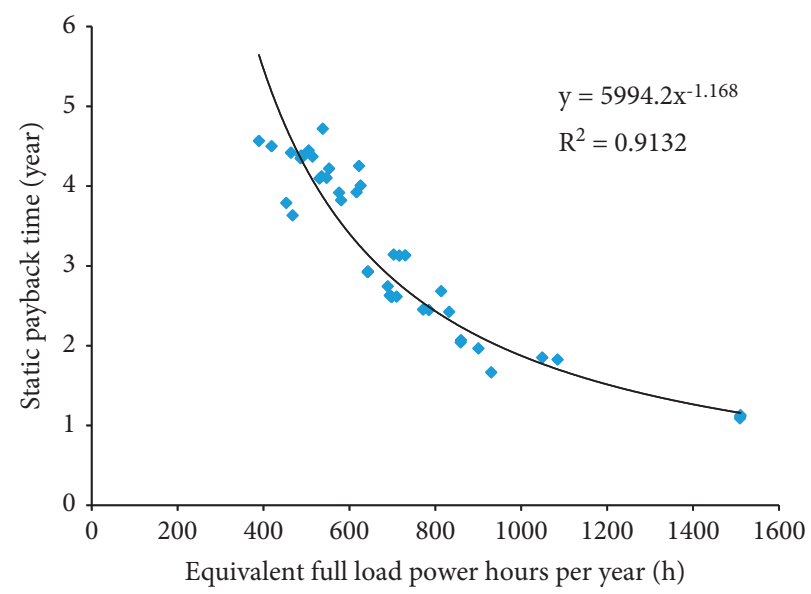

FIGURE 5: The relationship between the payback-years and full load hours with economy-first solutions.

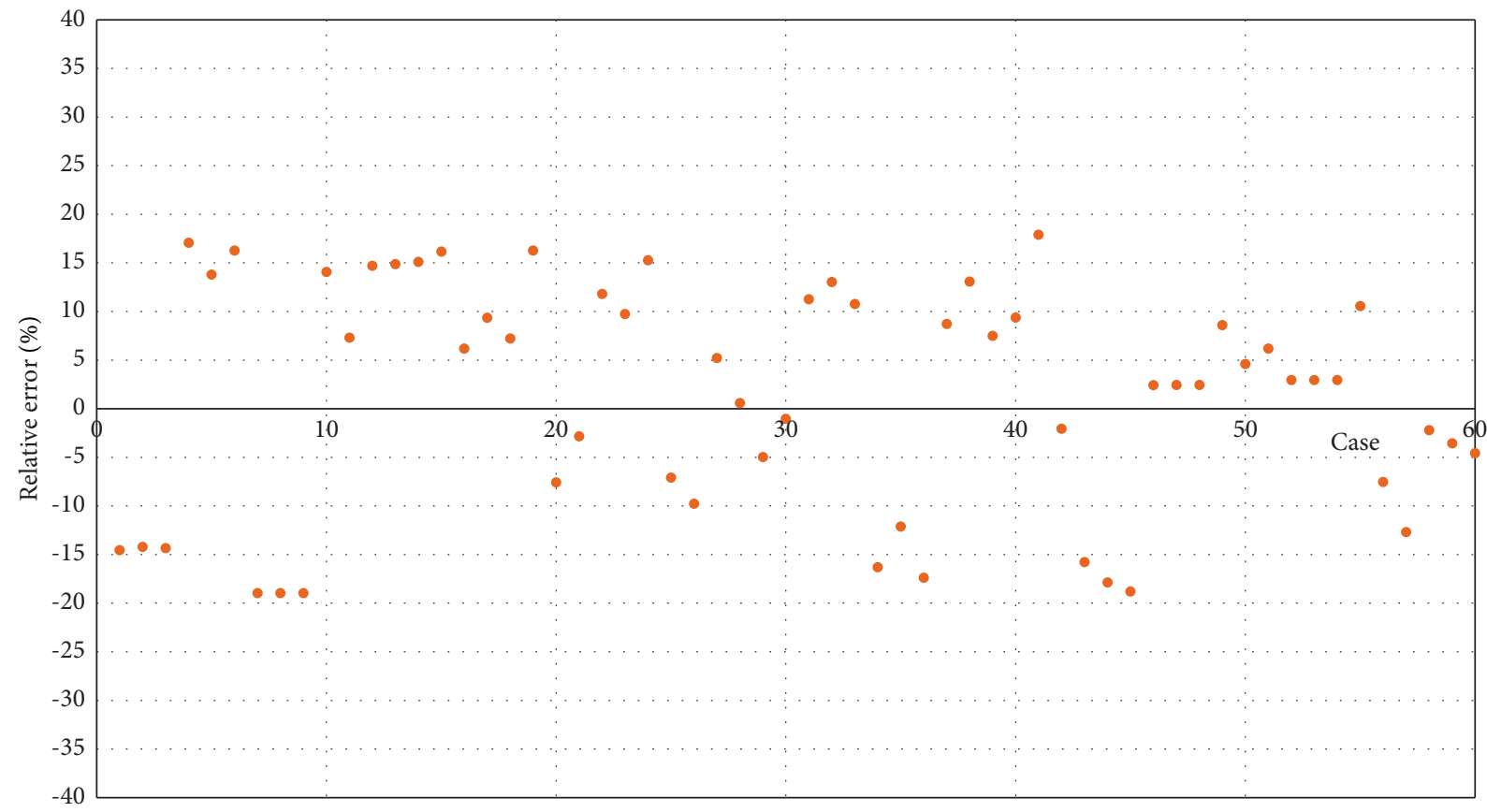

FiguRE 6: Forecast error based on regression relationships with economy-first solutions.

\section{Conclusion}

Through the economic analysis and comparison of 60 typical building integrated energy supply projects in four typical cities in China, the conclusions are as follows:

(1) The regional centralized comprehensive energy supply is a high-input low-return engineering project, and the investment payback period of a general project is more than 5 years.

The main income of general integrated energy supply projects comes from energy sales minus the difference between energy purchase costs and the operation and maintenance costs. The price of cooling and heating is mostly based on the energy supply cost of the air source heat pumps currently used on a large scale to determine the actual cost of cooling and heating. The current cost of cooling and heating in China is generally between 0.06 and $0.12 \$ / \mathrm{kWh}$. Considering that civil projects only have two seasons, winter and summer, and that the load varies greatly over time, the annual equivalent full-load energy supply hours are mostly less than $1500 \mathrm{~h}$. When there is no use of low-grade or low-cost renewable energy resources, the static investment payback period of most comprehensive energy supply projects is relatively long. Even if the most economical system scheme is adopted, the investment benefit of the integrated energy supply project is still poor.

(2) When the project adopts the currently widely adopted price pricing, the energy demand of the project is the fundamental factor that determines the 
economics of the project. In the early stage of the feasibility analysis, the annual equivalent full load hours can be used as a characteristic parameter to identify the economic feasibility of the project.

The static investment payback period of the optimal economic solution mostly depends on the annual equivalent full-load hours of the project, which can be predicted by the annual equivalent full-load hours. Using the regression relationship between the annual equivalent full-load energy supply hours and the static investment recovery period for prediction, the maximum error of 60 projects is $18.96 \%$, and the average error is $10.22 \%$.

Compared with current numerical and system dynamics model for point-to-point single system optimizing modeling, the proposed statistical regression model can help reveal the main factors of integrated energy system's economically feasible. Through the analysis of a large number of integrated energy system energy supply cases, it can be seen that the integrated energy supply system of the park is similar to the production system of a factory. When the annual commodity output or energy demand is sufficient, and the utilization rate of the production line is high, so the payback period of the factory or integrated energy system will be short. Therefore, when the integrated energy system adopts the optimized design scheme, the annual equivalent full load hours of the project have a key impact on the economics of the project. The integrated energy system scheme of the park can be obtained through the optimization model, and any project has the opportunity to choose the best system configuration at certain price system, but the load of the project depends on the project itself, and it is difficult to change from design. In a fair price market, even if the integrated energy system adopts the best design plan, the economics of the project still depend on the quality of the project's own energy demand: the closer the average hourly load to the maximum value, the shorter the project payback period.

It is worth mentioning that it is not hard to prove that the payback period of the integrated energy supply project will decrease with the increase of the annual equivalent full-load energy supply hours, which can be confirmed by formal reasoning. However, the specific quantitative relationship between the the payback period and annual equivalent full-load energy supply hours needs to be calculated based on the price system of gas, electricity, and equipment in each country. Although the relationship between the investment payback period and the annual equivalent full-load energy supply hours obtained in the article was not affected by climate and other factors, it is depending on the energy equipment price and energy price. The quantitative relationship is only applicable to similar equipment and energy mechanism, and it can be established from various price system.

\section{Data Availability}

The building load and calculation data used to support the findings of this study are included within the article.

\section{Conflicts of Interest}

The authors declare that they have no conflicts of interest.

\section{Acknowledgments}

The authors thank the State Grid Corporation of China Science and Technology Project "Integrated solution design and demonstration project construction for electrification projects in typical rural area" $(52182019000 \mathrm{~K})$ for their subsidies.

\section{References}

[1] S. Zou and T. Zhang, "CO2 emissions, energy consumption, and economic growth nexus: evidence from 30 provinces in China," Mathematical Problems in Engineering, vol. 2020, no. 5, 10 pages, Article ID 8842770, 2020.

[2] Y. Li, B. Wang, Z. Yang, J. Li, and G. Li, "Optimal scheduling of integrated demand response-enabled smart park integrated energy systems in uncertain environment," IEEE Transactions on Industry Applications, 2021.

[3] Y. Li, C. Wang, G. Li, and C. Chen, "Optimal scheduling of integrated demand response-enabled integrated energy systems with uncertain renewable generations: a Stackelberg game approach," Energy Conversion and Management, vol. 235, Article ID 113996, 2021.

[4] H. Lund and E. Münster, "Integrated energy systems and local energy markets," Energy Policy, vol. 34, no. 10, pp. 1152-1160, 2006.

[5] A. Abu-Rayash and I. Dincer, "Development of an integrated energy system for smart communities," Energy, vol. 202, Article ID 117683, 2020.

[6] Z. Huang, G. He, and H. G. Yan, "Overview and prospect of optimization model function for community-scale integrated energy system," Electric Power Automation Equipment, vol. 40, no. 1, pp. 10-18, 2020.

[7] A. Fattahi, J. Sijm, and A. Faaij, "A systemic approach to analyze integrated energy system modeling tools: a review of national models," Renewable and Sustainable Energy Reviews, vol. 133, Article ID 110195, 2020.

[8] Y. Xiang, H. Cai, C. Gu, and X. Shen, "Cost-benefit analysis of integrated energy system planning considering demand response," Energy, vol. 192, Article ID 116632, 2020.

[9] Z. Huang, H. Yu, and Z. Penng, "Urban energy system planning from wide area network perspective," Chinese Science Bulletin, vol. 63, no. Z2, pp. 3047-3058, 2018.

[10] B. Schminke, "Overview of the current state of research on characteristics and algorithms of energy management systems in households and buildings," International Journal of Energy Research, vol. 45, no. 10, pp. 14194-14206, 2021.

[11] Y. Wang, Y. Wang, Y. Huang et al., "Planning and operation method of the regional integrated energy system considering economy and environment," Energy, vol. 171, pp. 731-750, 2019.

[12] X. Liu, "Energy station and distribution network collaborative planning of integrated energy system based on operation optimization and demand response," International Journal of Energy Research, vol. 44, no. 6, pp. 4888-4909, 2020.

[13] S. Wei, Y. Li, L. Sun, J. Zhang, J. Shen, and Z. Li, "Stochastic model predictive control operation strategy of integrated energy system based on temperature-flowrate scheduling model considering detailed thermal characteristics," International Journal of Energy Research, vol. 45, no. 3, pp. 4081-4097, 2021.

[14] Z. Huang, H. Yu, X. Chu, and Z. Peng, "A novel optimization model based on game tree for multi-energy conversion systems," Energy, vol. 150, pp. 109-121, 2018. 
[15] M. R. Quitoras, P. E. Campana, P. Rowley, and C. Crawford, "Remote community integrated energy system optimization including building enclosure improvements and quantitative energy trilemma metrics," Applied Energy, vol. 267, Article ID 115017, 2020.

[16] A. H. Keshavarzzadeh and P. Ahmadi, "Multi-objective techno-economic optimization of a solar based integrated energy system using various optimization methods," Energy Conversion and Management, vol. 196, pp. 196-210, 2019.

[17] W. Meesenburg, T. Ommen, and B. Elmegaard, "Dynamic exergoeconomic analysis of a heat pump system used for ancillary services in an integrated energy system," Energy, pp. 154-165, 2018.

[18] L. Ge, S. Zhang, X. Bai, J. Yan, C. Shi, and T. Wei, "Optimal capacity allocation of energy storage system considering uncertainty of load and wind generation," Mathematical Problems in Engineering, vol. 2020, no. 10, 11 pages, Article ID 2609674, 2020.

[19] S. M. Mahmoudi, A. Maleki, and D. Rezaei Ochbelagh, "Optimization of a hybrid energy system with/without considering back-up system by a new technique based on fuzzy logic controller," Energy Conversion and Management, vol. 229, Article ID 113723, 2021.

[20] L. Langer and T. Volling, "An optimal home energy management system for modulating heat pumps and photovoltaic systems," Applied Energy, vol. 278, Article ID 115661, 2020.

[21] K. Ye, P. Li, and H. Li, "Optimization of hybrid energy storage system control strategy for pure electric vehicle based on typical driving cycle," Mathematical Problems in Engineering, vol. 2020, no. 1, 12 pages, Article ID 1365195, 2020.

[22] Y. Li, C. Wang, G. Li, J. Wang, D. Zhao, and C. Chen, "Improving operational flexibility of integrated energy system with uncertain renewable generations considering thermal inertia of buildings," Energy Conversion and Management, vol. 207, Article ID 112526, 2020.

[23] D. Yan, T. Hong, B. Dong et al., "IEA EBC Annex 66: definition and Simulation of occupant behavior in buildings," Energy and Buildings, vol. 156, pp. 258-270, 2017.

[24] J. Wang, H. Li, D. Wang, and J. Xu, "Research on operation characteristics of low temperature air source heat pump in North China," Building energy and Environment, vol. 38, no. 11, pp. 1-5, 2019.

[25] V. S. K. V. Harish and A. Kumar, "A review on modeling and simulation of building energy systems," Renewable and Sustainable Energy Reviews, vol. 56, pp. 1272-1292, 2016.

[26] A. L. Pisello, J. E. Taylor, X. Xu, and F. Cotana, "Inter-building effect: simulating the impact of a network of buildings on the accuracy of building energy performance predictions," Building and Environment, vol. 58, pp. 37-45, 2012.

[27] X. M. Guo, Y. G. Chen, W. H. Wang, and C. Z. Chen, "Experimental study on frost growth and dynamic performance of air source heat pump system," Applied Thermal Engineering, vol. 28, no. 17-18, pp. 2267-2278, 2008.

[28] C. A. De Swardt and J. P. Meyer, "A performance comparison between an air-source and a ground-source reversible heat pump," International Journal of Energy Research, vol. 25, no. 10, pp. 899-910, 2001.

[29] S. Hu, D. Yan, Y. Cui, and S. Guo, "Urban residential heating in hot summer and cold winter zones of China-Status, modeling, and scenarios to 2030," Energy Policy, vol. 92, pp. 158-170, 2016. 